\title{
The Physico-Chemical Properties of Sugar-Oxime-Ether Surfactants
}

\begin{abstract}
Sugar oxime ether surfactants are a new class of surfactants produced by the reaction of a sugar with a hydrophobic alkoxyamine, producing an oxime ether linkage. We examined nine examples of this class of surfactants. The sugars used were maltose, sucrose, and glyceraldehyde; the alkoxyamines were decyloxyamine, dodecyloxyamine, and adamantyloxyamine. For the resulting surfactants we determined their thermal stability, melting point, water solubility, effect on surface tension, and critical micelle concentration. We found that all the compounds tested were thermally stable and decreased substantially the surface tension of water.
\end{abstract}

Key words: Adsorption, renewable, sugar, saccharide, alkoxyamine

\begin{abstract}
Physikalisch-chemische Eigenschaften von Zuckeroximethertenside. Zuckeroximethertenside sind eine neue Tensidklasse, die durch Reaktion eines Zuckers mit einem hydrophoben Alkoxyamin unter Bildung einer Oximetherbindung hergestellt werden. Wir haben neun Beispiele aus dieser Tensidklasse untersucht. Die verwendeten Zucker waren Maltose, Saccharose und Glycerinaldehyd; die Alkoxyamine waren Decyloxyamin, Dodecyloxyamin und Adamantyloxyamin. Für die resultierenden Tenside haben wir die thermische Stabilität, den Schmelzpunkt, die Wasserlöslichkeit, den Einfluss auf die Oberflächenspannung und die kritische Mizellenbildungskonzentration bestimmt. Wir fanden, dass alle getesteten Verbindungen thermisch stabil waren und die Oberflächenspannung von Wasser wesentlich verringerten.
\end{abstract}

Stichwörter: Adsorption, Erneuerbar, Zucker, Saccharid, Alkoxyamin

\section{Introduction}

Modern society depends on ubiquitous use of chemicals in everyday life. Thus, the source and environmental fate of these chemicals (such as surfactants used in detergents, aircraft deicing fluids, and firefighting foams) are of great interest. Indeed, chemicals derived from renewable biomass have received recently a great deal of attention [1-6]. We became interested in sugar surfactants, a class of biocompatible nonionic surfactants which can be prepared by linking the renewable hydrophilic sugar moiety to a hydrophobic alkyl chain. Sugar-based surfactants are being considered for applications including personal-care products, food, and pharmaceuticals because they are considered environmentally sustainable [7]. In addition to their renewable nature, the sugar surfactants display physico-chemical properties that are insensitive to temperature, presumably due to the strength of the hydrogen bonding between the hydroxyl groups of the sugar headgroup and water [8]. Thus, sugar surfactants have been used in a variety of applications. For example, the commercially available sugar surfactant $n$-dodecyl- $\beta$-D-maltoside (DDM) (Figure 1 ) is commonly used to solubilize membrane proteins without altering their activity for gel electrophoresis [9-11]. Existing sugar surfactants, such as those shown in Fig. 1, use covalent linkages such as acetals, ethers, esters, or amides to tether the hydrophilic sugar head group to a hydrophobic alkyl chain. The syntheses often require selective protection and deprotection steps due to the relatively small reactivity differences of the hydroxyl groups on the sugar moiety [12]. Furthermore, the common covalent linkages of the existing sugar surfactants (Fig. 1) are prone to cleavage in aqueous acidic or basic media. This tendency often limits their use to neutral media.

To ameliorate the disadvantages of the existing sugar surfactants, we recently developed a synthesis route to a new class of sugar surfactants, sugar oxime ether surfactants (SOESurfs), that use the robust oxime ether bond to link the hydrophilic sugar headgroup to a hydrophobic alkyl chain (Fig. 2) [13]. The chemoselective formation of the oxime ether bond [14-18] obviates the synthetic complications involving selective protection and deprotection steps. Furthermore, the well-documented hydrolytic stability of the oxime ether bond [19-21] allows for the use of SOESurfs in acidic and basic media.

In this paper, we describe the SOESurf physicochemical characteristics, specifically their water solubility, thermal stability, melting point, effect on the surface tension of water, and the tendency to form micelles. We quantify the effect on surface tension using the model discussed below.

If the surfactant's affinity for the air-water interface is not dependent on surface coverage, the Gibbs adsorption isotherm can be integrated to yield the Szyszkowski equation: [22]

$\gamma=\gamma_{0}-\frac{\mathrm{RT}}{\omega} \ln \left(\mathrm{K}_{\mathrm{ad}} \mathrm{c}+1\right)$

In this equation, $\gamma$ is the surface tension of the solution, $\gamma_{0}$ is the surface tension of pure water, $\omega$ is the molar lateral surface area at full surface coverage, $\mathrm{K}_{\mathrm{ad}}$ is the equilibrium constant for surface adsorption, and $\mathrm{c}$ is the concentration. Thus, isotherms can be used to calculate the standard free energy change for adsorption to the air-water interface.

$\Delta_{\mathrm{ad}} \mathrm{G}^{\circ}=-\mathrm{RT} \ln \mathrm{K}_{\mathrm{ad}}$

For surfactants that form micelles, the critical micelle concentration (CMC) can be used to calculate the standard free energy change for micelle formation.

$\Delta_{\text {mic }} \mathrm{G}^{\circ}=\mathrm{RT} \ln \mathrm{CMC}$

Based on our results, we are gratified to find that six of the SOESurfs, $1 \mathrm{a}-3 \mathrm{a}$ and $1 \mathrm{~b}-3 \mathrm{~b}$, were quite good surfactants: all decreased the surface tension of water to less than $40 \mathrm{mN} \mathrm{m}^{-1}$ at sub-micromolar concentrations. 


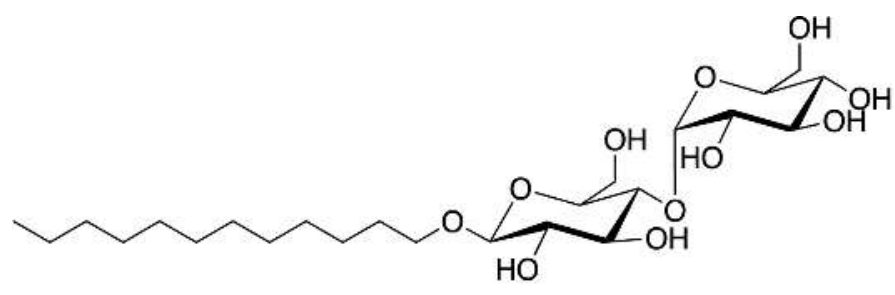

$n$-Dodecyl- $\beta$-D-maltoside (DDM)<smiles>CCCCCCCCCCCCCC(=O)OC1C(O)C(O)C(O)C(O)C(O)C(O)C1OC(O)C(O)CO</smiles>

6'-O-myristoyl maltose<smiles>CCCCCCCCCCCC(=O)N(C)CC(O)C(O)C(O)[C@H](O)CO</smiles>

$\mathrm{N}$-Lauroyl- $\mathrm{N}$-methylglucamide<smiles>CCCCCCCCCCCCNCC(O)C(O)C(O)[C@H](O)CO</smiles>

$\mathrm{N}$-Dodecylglucamine

Figure 1 Representative sugar surfactants<smiles>CCCON=CC(O)CO</smiles>

1a $\mathrm{n}=8$ (Dec-ON=GLA)

2b $n=10$ (Dodec-ON=GLA)<smiles>CCCCO/N=C/C(O)C(O)C(O)C(O)CO</smiles>

4a $n=8($ Dec-ON=GLC) 5b $\mathrm{n}=10$ (Dodec-ON=GLC)

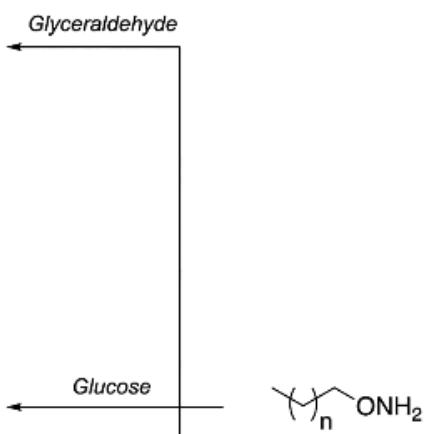

$\mathrm{n}=8\left(\mathrm{Dec}-\mathrm{ONH}_{2}\right)$ b $\mathrm{n}=10\left(\right.$ Dodec-ONH $\left.\mathrm{N}_{2}\right)$

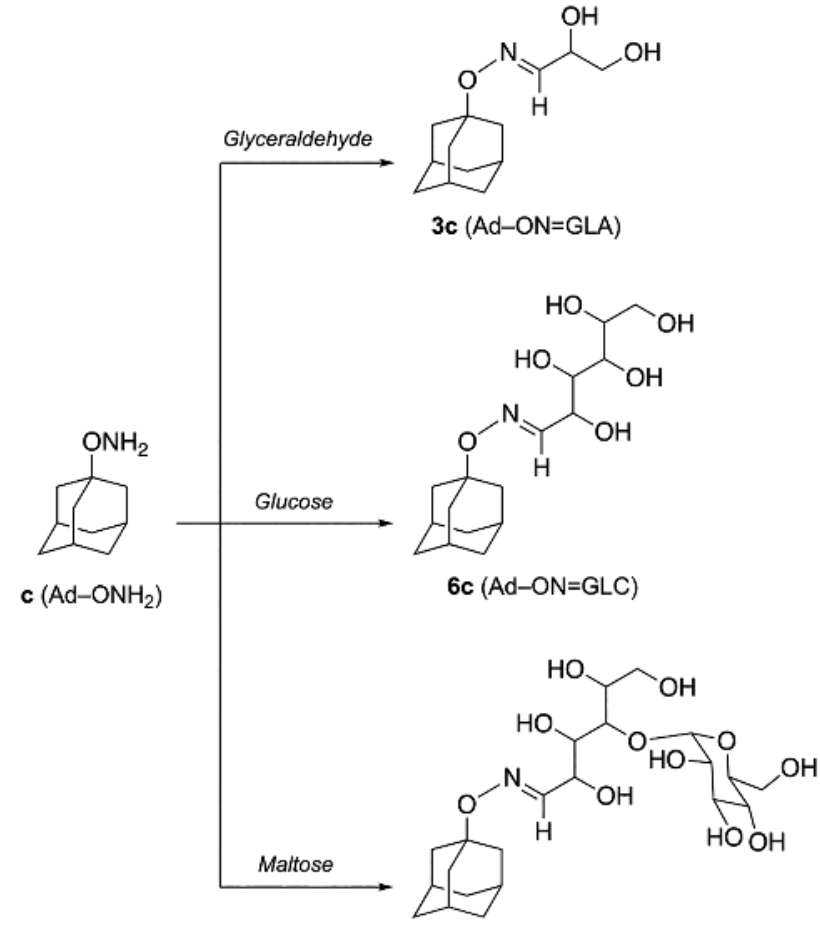

$9 c(A d-O N=M A L T)$

7 a $n=8$ (Dec-ON=MALT)

8b $n=10$ (Dodec-ON=MALT)

Figure 2 Sugar oxime ether surfactants (SOESurfs). The hydrophobes are decyl-, dodecyl-, and adamantyl-groups, while the sugar hydrophiles are glyceraldehyde, glucose, and maltose. The abbreviations for the sugar hydrophiles on SOESurf: GLA= glyceraldehyde; GLC = glucose; MALT = maltose

2 Materials and Methods

\subsection{Materials}

All SOESurfs were synthesized and purified as described in our other work [13]. The water used for all experiments was $18 \mathrm{M} \Omega \mathrm{cm}$ produced using a Barnstead NANOpure system.

\subsection{Methods}

\subsubsection{Melting point}

The melting points were determined by placing the compounds in $100-\mathrm{mm}$ glass capillary tubes. The tubes were heated while being observed under 6x magnification using Vernier Melt Stations (Vernier Software \& Technology, Beaverton, Oregon). 


\subsubsection{Solubility}

The procedure used to determine solubility was adapted from a literature procedure [23]. Approximately $20 \mathrm{mg}$ of the surfactant to be tested was mixed with $20 \mathrm{~mL}$ of nanopure water in a vial. The mixture was magnetically stirred overnight at $25^{\circ} \mathrm{C}$. If all solids had dissolved, an additional $10 \mathrm{mg}$ of solid was added, and the overnight stirring was repeated. The mixture was then stirred for $24 \mathrm{~h}$ at $25^{\circ} \mathrm{C}$. If the mixture did not have excess solid after $24 \mathrm{~h}$, the addition and stirring steps were repeated. Once a saturated solution had formed, the solution was filtered using a Pasteur pipette packed with glass wool. A 5-mL aliquot of the glass wool filtered, saturated solution was filtered through a $45 \mu \mathrm{m}$ syringe filter and lyophilized to constant mass over $24-72 \mathrm{~h}$. The mass of the dry residue was used to calculate the solubility.

\subsubsection{Thermogravimetric analysis}

Thermogravimetric analysis (TGA) was used to determine the thermal stability of the surfactants in an inert (dry nitrogen) atmosphere. A TA Instrument TGA Q500 was used for all experiments, with a nitrogen flow rate of $90 \mathrm{~mL} \mathrm{~min}^{-1}$ in the sample chamber. The samples were taken from ambient temperature to $300^{\circ} \mathrm{C}$ at a rate of $10^{\circ} \mathrm{C}$ per minute.

\subsubsection{Modeling analysis}

The solvent-accessible polar and non-polar area for each surfactant was estimated using Spartan ${ }^{\mathrm{TM}}$ (Wavefunction, Inc, Irvine, CA). First, each molecule was subjected to a simple molecular mechanics minimization. Then, the geometry was optimized using density functional theory (B3LYP using a $6-31$ * basis set), with water as the solvent. The polar and non-polar solvent-accessible areas were calculated using the built-in Quantitative Structure-Activity Relationship (QSAR) option in Spartan ${ }^{\mathrm{TM}}$. The probe radius for calculating the accessible area was 1.0 A. The cutoff for polar area was a calculated electrostatic potential with an absolute value greater than $75 \mathrm{~kJ} / \mathrm{mol}$.

\subsubsection{Surface tension isotherms}

A KSV Sigma 703 tensiometer employing a platinum DuNoüy ring was used for all surface tension measurements. The DuNoüy ring was cleaned by heating with a propane torch flame until red hot. The instrument was set to report all surface tension measurements using the Zuidema-

\begin{tabular}{|c|c|c|}
\hline Surfactant(tail-ON=sugar) & $\mathrm{T}_{\mathrm{ded}}{ }^{\circ} \mathrm{C}$ & $\mathrm{T}_{\mathrm{m}} /{ }^{\circ} \mathrm{C}$ \\
\hline Ad-ON=GLA (3c) & 215 & $81-82$ \\
\hline Ad-ON=GLC (6c) & 217 & $104-107$ \\
\hline Ad-ON=MALT (9c) & 221 & $114-117$ \\
\hline Dec-ON=GLA (1a) & 214 & $39-41$ \\
\hline Dec-ON=GLC (4a) & 219 & $169-171$ \\
\hline Dec-ON=MALT (7a) & 204 & decomposes \\
\hline Dodec-ON=GLA (2b) & 202 & $52-54$ \\
\hline Dodec-ON=GLC (5b) & 237 & $146-148$ \\
\hline Dodec-ON=MALT (8b) & 215 & decomposes \\
\hline
\end{tabular}

Table 1 Decomposition and Melting Temperatures of SOESurfs
Waters correction factor. Stock solutions of each surfactants were prepared at concentrations approximately half of the solubility limit for each compound. A series of $2: 1$ serial dilutions were prepared, continuing until the most dilute solution was less than $5 \mu \mathrm{M}$ in surfactant. Solutions were held in a $25^{\circ} \mathrm{C}$ water bath until use.

\section{Results}

\subsection{Melting Point and Thermal Stability}

The results of melting point and thermogravimetric analysis are shown in Table 1. All the surfactants are stable in dry nitrogen below $200^{\circ} \mathrm{C}$. All surfactants were solids at room temperature.

\subsection{Solubility and Surface Adsorption}

All the SOESurfs decreased the surface tension of water. One measure of surfactant efficiency is the concentration of surfactant needed to produce a given decrease in surface tension. A commonly used parameter is $\mathrm{pC}_{20}$, the negative base 10 logarithm of the surfactant concentration (in mol $\mathrm{L}^{-1}$ ) that induces a $20 \mathrm{mN} \mathrm{m}^{-1}$ decrease in surface tension [24]. Efficient surfactants will have high values of $\mathrm{pC}_{20}$. The solubility and the surfactant efficiency, $\mathrm{pC}_{20}$, of SOESurfs in water are summarized in Table 2. The surfactants with maltose headgroups had solubilities that were, on average, an order of magnitude more than the surfactants made from glyceraldehyde or glucose.

The adsorption isotherms of the SOESurfs are shown in Fig. 3. Four of the SOESurfs (7a, 8b, 1a, 2b) formed micelles, as shown by the breaks in the isotherms in Fig. 3.

The results from the analyzing the isotherm data in Fig. 3 are shown in Table 3.

Five of the SOESurfs did not form micelles: surfactants with an adamantyl tail (3c, 6c, 9c) or with a glucose headgroup $(\mathbf{4 a}, \mathbf{5 b})$. The isotherms for these surfactants are shown in Fig. 4.

The results from the analyzing the isotherm data in Fig. 4 are shown in Table 4.

\section{Discussion}

\subsection{Melting Point and Thermal Stability}

For a given hydrophobe, the melting point increased with the size of the sugar in the head group. In addition, the decyl and dodecyl maltose SOESurfs 7a, 8b (Fig. 2) became translucent at approximately $80^{\circ} \mathrm{C}$. This may be a solid to liquid-crystal phase transition; similar surfactants, such as decyl $\alpha$-D-glucopyranoside, dodecyl $\alpha$-D-glucopyranoside, decyl $\beta$-D-glucopyranoside, and dodecyl $\beta$-D-glucopyranoside are known to display a solid to smectic liquid crystalline phase transition $[25,26]$. However, we did not attempt to characterize this transition.

\subsection{Solubility and Surface Adsorption}

As expected, SOESurfs with maltose head groups all have relatively high solubility in water. This is likely a consequence of the large polar area of this group, shown by the calculated solvent-accessible polar area (Table 2). Surprisingly, SOESurfs with the adamantyl hydrophobe display high solubility in water despite the rigid nature of the adamantyl group. For solid compounds, solubility normally is lower for rigid compounds, since flexible molecules gain more entropy when 


\begin{tabular}{|c|c|c|c|c|}
\hline SOESurf (tail-ON=sugar) & Solubility/mM & Efficiency $\left(\mathrm{pC}_{20}\right)$ & Polar Area/ $\AA^{2}$ & ${\text { Nonpolar Area/ } \AA^{2}}^{2}$ \\
\hline Ad-ON=GLA (3c) & $14 \pm 1$ & $2.54 \pm 0.05$ & 27 & 131 \\
\hline Ad-ON=GLC (6c) & $26 \pm 2$ & $2.16 \pm 0.06^{a}$ & 59 & 137 \\
\hline Ad-ON=MALT (9c) & $77 \pm 4$ & $1.99 \pm 0.10$ & 79 & 171 \\
\hline Dec-ON=GLA (1a) & $5.9 \pm 0.5$ & $4.60 \pm 0.10$ & 41 & 185 \\
\hline Dec-ON=GLC (4a) & $2.4 \pm 0.2$ & $4.06 \pm 0.06$ & 48 & 215 \\
\hline Dec-ON=MALT (7a) & $94 \pm 2$ & $3.70 \pm 0.11$ & 84 & 194 \\
\hline Dodec-ON=GLA (2b) & $1.7 \pm 0.2$ & $4.60 \pm 0.12$ & 32 & 206 \\
\hline Dodec-ON=GLC (5b) & $1.6 \pm 0.1$ & $4.42 \pm 0.12$ & 47 & 237 \\
\hline Dodec-ON=MALT (8b) & $80 \pm 8$ & $4.61 \pm 0.03$ & & \\
\hline
\end{tabular}

${ }^{\text {a }}$ This value was obtained by extrapolation.

Table 2 Solubility and Adsorption Efficiency at $25^{\circ} \mathrm{C}$

$\mathbf{A}$

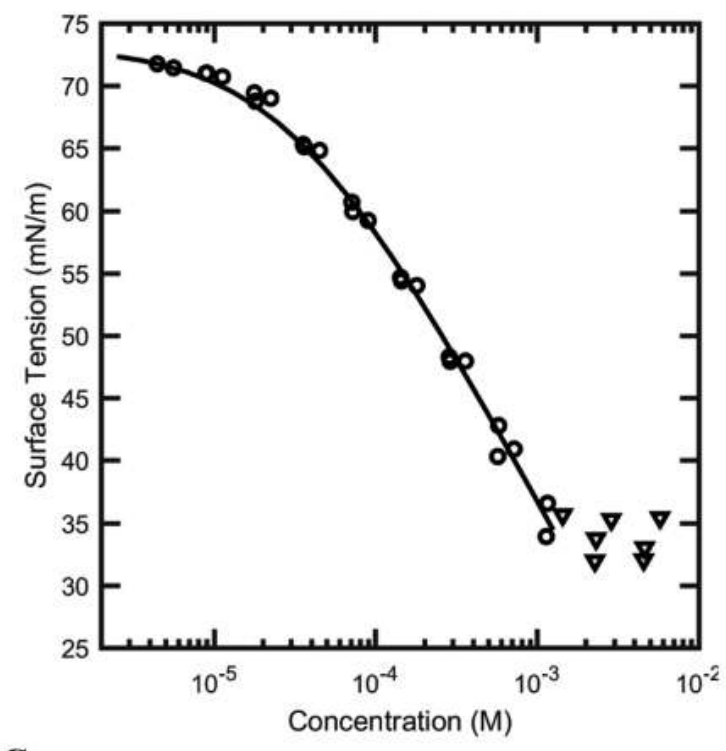

C

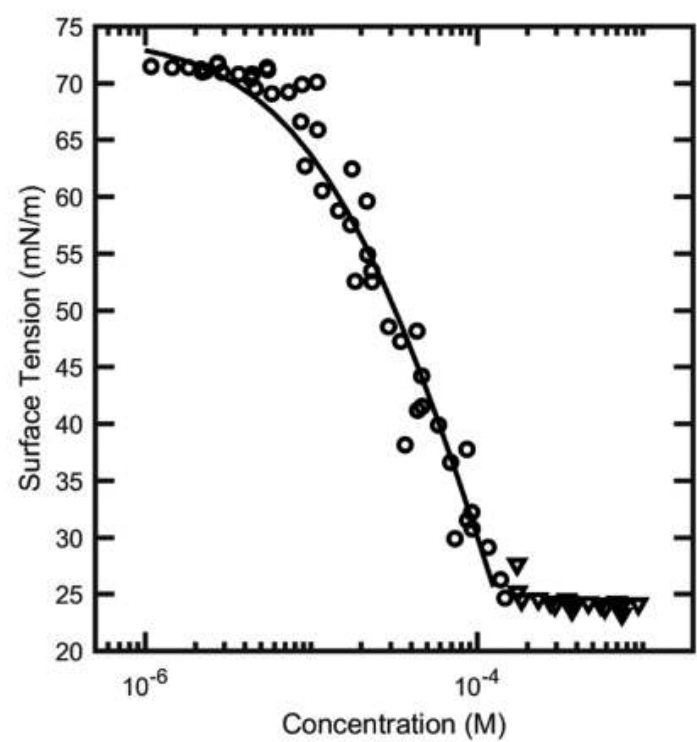

$\mathbf{B}$

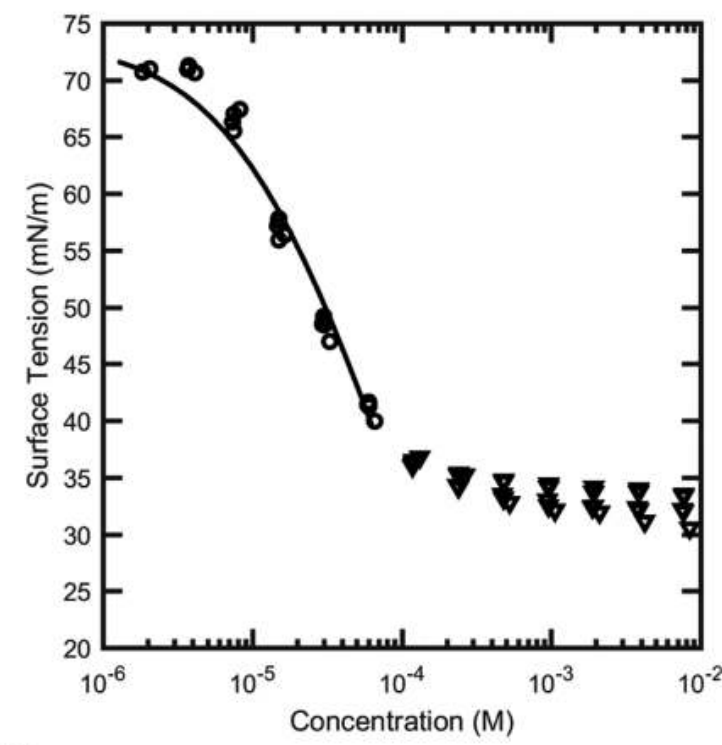

D

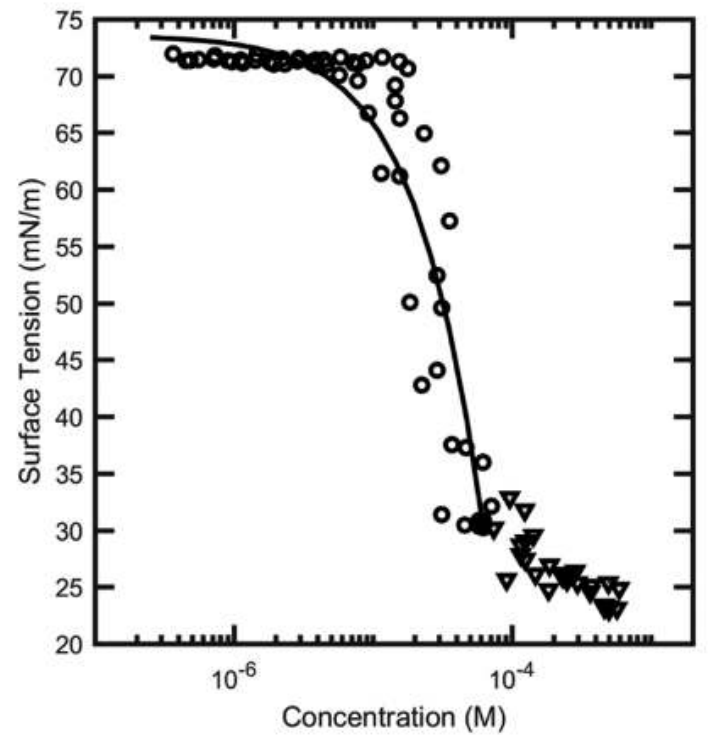

Figure 3 The surface tension isotherm data for four of the SOESurfs show a break at the critical micelle concentration. Data at concentrations lower than the CMC (o) were fit to the Szyszkowski equation; data above the CMC ( $\nabla)$ were not. (A) Dec-ON=MALT (7a), (B) Dodec-ON=MALT (8b), (C) Dec-ON=GLA (1a), (D) Dodec-ON=GLA (2b) 
they dissolve [27]. However, SOESurfs with the adamantyl hydrophobe have a lower solvent-accessible non-polar area than those with a straight chain hydrophobe (Table 2), which probably accounts for their higher than expected solubility in water.

The adsorption isotherms of all nine SOESurfs indicate that they are effective surfactants. The SOESurfs with a dodecyl hydrophobe have surfactant efficiencies very close to that of the commercially-available $n$-dodecyl- $\beta$-D-maltoside, with a $\mathrm{pC}_{20}$ of 4.52 [28]. The SOESurfs with a decyl hydrophobe have efficiencies similar to that of the commerciallyavailable $n$-decyl- $\beta$-D-maltoside, with a $\mathrm{pC}_{20}$ of 3.77 [29].

For surfactants with the same hydrophilic headgroup we observed that the polar area varies very little with the type of hydrophobic tail. For a given headgroup, the polar areas are essentially the same for surfactants with dodecyl and decyl tails; there was no clear pattern for the adamantyl tails. In contrast, the non-polar area increased in the order adamantyl < decyl < dodecyl regardless of the headgroup. Since adsorption is driven by the hydrophobic effect, we were not surprised to see that, in general, the surfactant efficiency increased in the same order: adamantyl $\ll$ decyl $<$ dodecyl.

For surfactants with the same hydrophobic tails we observe that, as expected, polar area increased with the num- ber of hydroxyl groups of the sugar hydrophilic headgroup: GLA < GLC < MALT. Nonpolar area also increased, but not nearly as much. The increasing polar area appears to decrease the affinity of the surfactants for the surface, as the surfactant efficiency decreased in the same order: GLA > GLC > MALT. The sole exception to this trend was compound $8 \mathbf{b}$, which had the highest efficiency of the surfactants despite bearing a maltose headgroup.

We see in Table 3 that the SOESurfs with the bulky maltose headgroups had larger molar surface areas than those with glyceraldehyde. The magnitudes of the free energies for micelle formation and adsorption at the air-water interface are higher for SOESurfs with dodecyl tails than for those with decyl tails.

Finally, it is important to note that the magnitude of the micelle formation free energy is always less than that for adsorption at the air-water interface. A rough estimate of this difference in energy can be calculated by accounting for the portion of $\Delta_{\mathrm{ad}} \mathrm{G}^{\circ}$ due to the decrease in surface energy at the air-water interface:

$\Delta_{\mathrm{ad}} \mathrm{G}^{\circ}-\Delta_{\mathrm{miC}} \mathrm{G}^{\circ} \approx\left(\gamma_{\mathrm{CMC}}-\gamma_{0}\right) \omega$

\begin{tabular}{|c|c|c|c|c|}
\hline SOESurf & $\boldsymbol{\omega} / \mathrm{m}^{2} \mathrm{mmol}^{-1}$ & $\boldsymbol{\Delta}_{\mathrm{ad}} \mathrm{G}^{\circ} / \mathrm{kJ} \mathrm{mol}^{-1}$ & $\mathrm{CMC} / \boldsymbol{\mu M}$ & $\boldsymbol{\Delta}_{\mathrm{mic}} \mathrm{G}^{\circ} / \mathrm{kJ} \mathrm{mol}^{-1}$ \\
\hline Dec-ON=GLA (1a) & $103 \pm 8$ & $-26.2 \pm 0.9$ & 160 & $-21.6 \pm 0.5$ \\
\hline Dec-ON=MALT (7a) & $220 \pm 40$ & $-24.9 \pm 0.8$ & 1460 & $-16.1 \pm 0.4$ \\
\hline Dodec-ON=GLA (2b) & $80 \pm 40$ & $-26 \pm 2$ & 56 & $-23.7 \pm 0.8$ \\
\hline Dodec-ON=MALT (8b) & $190 \pm 30$ & $-29.1 \pm 0.9$ & 110 & $-22.4 \pm 0.5$ \\
\hline
\end{tabular}

a All free energy values were calculated using a $1.0 \mathrm{M}$ standard state.

Table 3 Molar Area and Free Energy of Adsorption and Micelle Formation at $25^{\circ} \mathrm{C}$
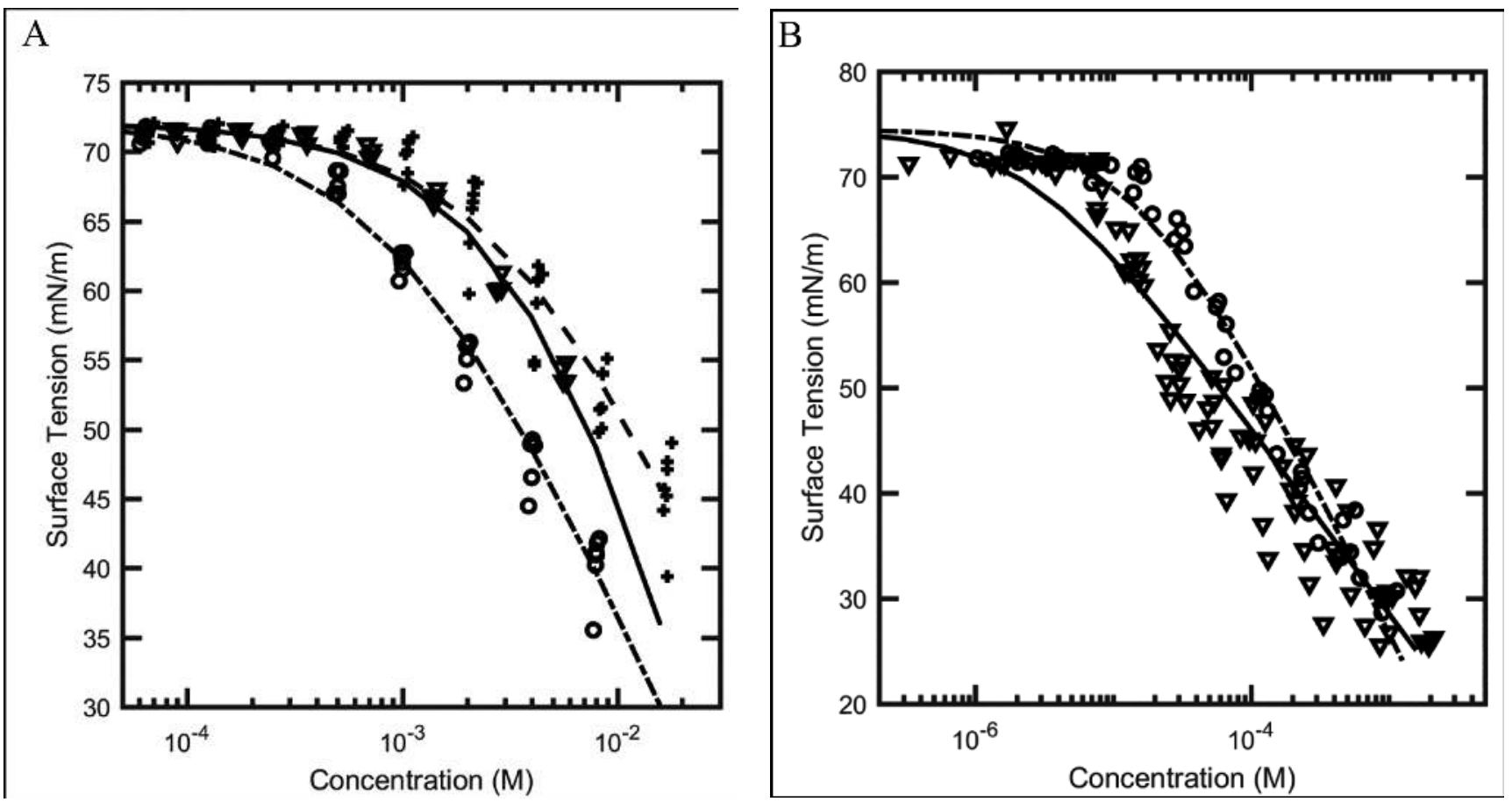

Figure 4 The surface tension isotherm data for non-micelle forming surfactants: $(A)$ Ad-ON=GLA (3c) $(0), A d-O N=G L C(6 c)(\nabla), A d-O N=M A L T(9 c)(+)$ and (B) Dec-ON=GLC (4a) (o) and Dodec-ON=GLC (5b) ( $\nabla)$. Note that surfactants with an adamantyl tail (3c, 6c, and $9 c)$ are much less effective at reducing surface tension significantly at low concentration. 


\begin{tabular}{|c|c|c|}
\hline SOESurf & $\boldsymbol{\omega} / \mathrm{m}^{2} \mathrm{mmol}^{-1}$ & $\boldsymbol{\Delta}_{\mathrm{ad}} \mathrm{C}^{\circ} / \mathrm{kJ} \mathrm{mol}^{-1}$ \\
\hline Ad-ON=GLA (3c) & $166 \pm 8$ & $-16.8 \pm 0.4$ \\
\hline Ad-ON=GLC (6c) & $80 \pm 20$ & $-12.1 \pm 0.2$ \\
\hline Ad-ON=MALT (9c) & $120 \pm 30$ & $-12.6 \pm 0.8$ \\
\hline Dec-ON=GLC (4a) & $200 \pm 30$ & $-26.1 \pm 0.8$ \\
\hline Dodec-ON=GLC (5b) & $300 \pm 20$ & $-30.7 \pm 0.9$ \\
\hline
\end{tabular}

a All free energy values were calculated using a $1.0 \mathrm{M}$ standard state.

Table 4 Molar Area and Free Energy of Adsorption at $25^{\circ} \mathrm{C}$

Here $\gamma_{\mathrm{CMC}}$ is the surface tension at the CMC. For example, the molar area for Dec-ON=GLA is $103,000 \mathrm{~m}^{2} \mathrm{~mol}^{-1}$ and $\gamma_{\mathrm{CMC}}$ is $\sim 25 \mathrm{~N} \mathrm{~m}^{-1}$; thus, the predicted difference between of $\Delta_{\text {ad }} \mathrm{G}^{\circ}$ and $\Delta_{\text {mic }} \mathrm{G}^{\circ}$ is $4.8 \mathrm{~kJ} \mathrm{~mol}^{-1}$. The observed difference is $4.6 \mathrm{~kJ} \mathrm{~mol}^{-1}$. This difference is larger for the maltose-based SOESurfs, which is expected as a consequence of their large headgroups.

The presence of the oxime ether linkages does not have a measurable effect on the value of the free energy of micelle formation, as shown by a comparison of the value for Dodec-ON=MALT, $-22.4 \mathrm{~kJ} \mathrm{~mol}^{-1} \pm 0.5 \mathrm{~kJ} \mathrm{~mol}^{-1}$, with that of the commercially-available surfactant $n$-dodecyl- $\beta$-D-maltoside, $-21.8 \mathrm{~kJ} \mathrm{~mol}^{-1}$ [29].

The low affinity of the SOESurfs with adamantyl tails for the air-water interface is striking. These surfactants are less hydrophobic than the others because of their lower hydrophobic accessible area, as shown in Table 2.

\subsection{CMC and molecular structure}

We expected that surfactants with longer chains would have smaller CMC values because of their greater hydrophobicity. This was observed in the data: changing from a decyl to a dodecyl chain decreased the CMC for all surfactants that formed micelles. The size of the decrease was different for different headgroups: a factor of approximately three for surfactants with GLA headgroups and a factor of approximately 13 for surfactants with MALT headgroups.

The headgroup type affects the CMC:Surfactants with a GLA headgroup had smaller CMC values than surfactants with MALT headgroups. The decrease in CMC was a factor of about nine for decyl-chain surfactants and about two for dodecyl-chain surfactants.

\section{Conclusions}

The oxime ether linkage provides a route to chemically robust surfactants sourced from a renewable feedstock. All nine SOESurfs tested were effective at decreasing surface tension. SOESurfs with straight-chain hydrophobes all resulted in substantial surface tension decreases at micromolar concentrations; SOESurfs with adamantyl hydrophobes did this only at millimolar concentrations. Our results suggest several areas for future work. First, the suspected liquid crystalline phase behavior for Dec-ON=MALT and DodecON=MALT could be characterized. Second, since the most promising surfactants were based on maltose and a straight-chain hydrophobe, we would like to synthesize and characterize maltose-based SOESurfs with 14 and 16-carbon chains. Finally, SOESurfs with large hydrophobes would be water insoluble. It is possible that such compounds would form bilayers and vesicles.

\section{Acknowledgements}

We gratefully thank the Department of the Navy, Office of Naval Research, under Award \# N00014-11-1-0359 for sponsoring this work.

\section{References}

1. Lozsan, A., Rivas, I., Rodriguez, G., Martinez, S. and Pérez, M. Á.: Determination of Surface-Active Characteristics of a Natural Surfactant Extracted from Sapindus Saponaria, Tenside Surfactants Deterg. 54 (2017) 109- 117. DOI: 10.3139/113.11049

2. Lin, L.-H., Su, S.-K., Lai, Y.-C. and Yang, Y.-H.: Physicochemical Properties of Amino Acid Surfactants and Their Use in Dyeing with Natural Plant Dyes, Tenside Surfactants Deterg. 54 (2017) 353-360. DOl: 10.3139/113.110507

3. Markovic, D. B., Tasic-Kostov, M., Lukic, M., Isailovic, T., Krstonosic, V., Daniels, $R$. and Savic, S.: Physicochemical Characterization and in vivo Skin Performance of a Novel Alkyl Polyglucoside Emulsifier in Natural Cosmetic CreamBases, Tenside Surfactants Deterg. 51 (2014) 133- 145. DOI: $10.3139 / 113.110294$

4. Caes, B. R., Teixeira, R. E., Knapp, K. G. and Raines, R. T.: Biomass to Furanics: Renewable Routes to Chemicals and Fuels, ACS Sustain. Chem. Eng. 3 (2015) 2591 - 2605. DOI: 10.1021/acssuschemeng.5b00473

5. Gusain, R., Dhingra, S., Khatri and O. P.: Fatty-Acid-Constituted Halogen-Free Ionic Liquids as Renewable, Environmentally Friendly, and High-Performance Lubricant Additives, Ind. Eng. Chem. Res. 55 (2016) 856-865. DOI: 10.1021/acs.iecr.5b03347

6. Tan, J. P. Md. Jahim, J.,Wu, T. Y. Harun, S., Kim, B. H. and Mohammad, A. W. Insight into biomass as a renewable carbon source for the production of succinic acid and the factors affecting the metabolic flux toward higher succinate yield, Ind. Eng. Chem. Res. 53 (2014) 16123-16134. DOl:10.1021/ie502178j

7. Allen, D. K. and Tao, B. Y.: Carbohydrate-alkyl ester derivatives as biosurfactants, J. Surfactants Deterg. 2 (1999) 383-390. DOI: 10.1007/s11743-999-0093-4

8. Söderman, O. and Johansson, I.: Polyhydroxyl-based surfactants and their physico-chemical properties and applications, Curr. Opin. Colloid Interface Sci. 4 (1999) 391 - 401. DOI:10.1016/S1359-0294(00)00019-4

9. Witzmann, F., Jarnot, B. and Parker, D.: Dodecyl maltoside detergent improves

\section{SWISS'tatest}

Swissatest Testmaterialien AG Mövenstrasse 12 swissatest.ch $\mathrm{CH}-9015$ St.Gallen phone +41713118055 fax +41713118057

\section{MATERIALS AND TESTING IN THE DOMAINS OF WASHING, CLEANING AND HYGIENE.}

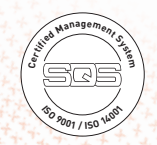

+ standardised soiled test fabrics

+Test material for leather

+ Testing of washing systems

+ Testing of detergents and enzymes

+ Hygiene assessment 
resolution of hepatic membrane proteins in two-dimensional gels., Electrophoresis. 12 (1991) 687-8. PMid:1752256; DOl:10.1002/elps.1150120919

10. Luche, S., Santoni, V. and Rabilloud, T.: Evaluation of nonionic and zwitterionic detergents as membrane protein solubilizers in two-dimensional electrophoresis, Proteomics. 3 (2003) 249-253. PMid:12627377; DOI: 10.1002/pmic.200390037

11. Crichton, P. G., Harding, M., Ruprecht, J. J., Lee, Y. and Kunji, E. R. S., Lipid, detergent, and Coomassie Blue G-250 affect the migration of small membrane proteins in blue native gels: mitochondrial carriers migrate as monomers not dimers., J. Biol. Chem. 288 (2013) 22163-73. PMid:23744064 DOI:10.1074/jbc.M113.484329

12. Rybinski, W. Von and Hill, K.: Alkyl Polyglycosides-Properties and Applications of a new Class of Surfactants, Angew. Chem. Int. Ed. 37 (1998) 1328- 1345. DOI:10.1002/(SICI) 1521-3773(19980605)37:10<1328::AIDANIE $1328>3.0 . C O ; 2-9$

13. Ewan, H. S., Muli, C. S., Touba, S., Bellinghiere, A. T., Veitschegger, A. M., Smith, T. B., Pistel, W. L., Jewell, W. T., Rowe, R. K., Hagen, J. P. and Palandoken, H.: Synthesis of sugar oxime ether surfactants, Tetrahedron Lett. 55 (2014) 4962 - 4965. DOI:10.1016/j.tetlet.2014.07.036

14. Kolb, H. C., Finn, M. G. and Sharpless, K. B.: Click Chemistry: Diverse Chemica Function from a Few Good Reactions, Angew. Chem. Int. Ed. Engl. 40 (2001) 2004-2021.

DOI:10.1002/1521-3773(20010601)40:11<2004::AID-ANIE2004>3.0.CO;2-5

15. Marcaurelle, L. a, Shin, Y., Goon, S. and Bertozzi, C. R.: Synthesis of oximelinked mucin mimics containing the tumor-related $\mathrm{T}(\mathrm{N})$ and sialyl $\mathrm{T}(\mathrm{N})$ antigens., Org. Lett. 3 (2001) 3691 -4. PMid:11700114; DOI:10.1021/ol0166247

16. Perouzel, E., Jorgensen, M. R. Keller, M. and Miller, A. D.: Synthesis and formulation of neoglycolipids for the functionalization of liposomes and lipoplexes., Bioconjug. Chem. 14 (2003) 884-98. PMid:13129391 DOI: 10.1021/bc034068q

17. Sadamoto, R., Niikura, K., Ueda, T., Monde, K., Fukuhara, N. and Nishimura, S. 1.: Control of bacteria adhesion by cell-wall engineering., J. Am. Chem. Soc. 126 (2004) 3755-61. PMid:15038728; DOI:10.1021/ja039391i

18. Biswas, S., Huang, X., Badger, W. R. and Nantz, M. H.: Nucleophilic cationization reagents., Tetrahedron Lett. 51 (2010) 1727 - 1729. PMid:20204160; DOI: 10.1016/j.tetlet.2010.01.094

19. Kalia, J. and Raines, R. T.: Hydrolytic stability of hydrazones and oximes., Angew. Chem. Int. Ed. Engl. 47 (2008) 7523 - 6. PMid: 18712739; DOl: 10.1002 /anie.200802651

20. Corsaro, A., Chiacchio, U. and Pistara, V.: Regeneration of Carbonyl Compounds from the Corresponding Oximes, Synthesis (Stuttg). (2001) 1903. DOI: $10.2174 / 138527209787582259$

21. Brunner, H., Scho, M. and Zabel, M.: Enantioselective catalysis. Part 142: Carbohydrate-derived oxime ethers from functionalised aldehydes and $\mathrm{O}-\mathrm{b}-\mathrm{D}$ glucopyranosylhydroxylamine - new C N ligands stable towards hydrolysis † 12 (2001) 2671-2675. DOI:10.1016/S0957-4166(01)00451-7

22. Bresler, M. R. and Hagen, J. P.: Surfactant Adsorption: A Revised Physical Chemistry Lab, J. Chem. Educ. 85 (2008) 269. DOI:10.1021/ed085p269

23. Lee, L. and Huang, H.: Solubility of Tetrabutylammonium Bromide in Benzene between 298.15 K and 323.15 K, J. Chem. Eng. Data. 47 (2002) 1135- 1139. DOI: 10.1021/je010320d

24. Rosen, M. J. and Kunjappu, J. T.: Surfactants and Interfacial Phenomena, John Wiley \& Sons, 2012. DOl:10.1002/9781118228920

25. Boyd, B. J., Drummond, C. J., Krodkiewska, I. and Grieser, F.: How Chain Length. Headgroup Polymerization, and Anomeric Configuration Govern the Thermotropic and Lyotropic Liquid Crystalline Phase Behavior and the Air-Water Interfacial Adsorption of Glucose-Based Surfactants, Langmuir. 16 (2000) 7359-7367. DOI:10.1021/la991573w

26. Vill, V., von Minden, H. M., Koch, M. H. J., Seydel, U. and Brandenburg, K.: Thermotropic and lyotropic properties of long chain alkyl glycopyranosides. Part II. Disaccharide headgroups, Chem. Phys. Lipids. 106 (2000) 157- 179 DOI: 10.1016/s0009-3084(99)00119-x

27. Delaney, J. S., ESOL: estimating aqueous solubility directly from molecular structure, J. Chem. Inf. Comput. Sci. 44 (2004) 1000 - 1005. PMid: 15154768 DOI: 10.1021/ci034243x

28. Hines, J. D., Thomas, R. K., Garrett, P. R., Rennie, G. K. and Penfold, J.: Investigation of Mixing in Binary Surfactant Solutions by Surface Tension and Neutron Reflection: Anionic/Nonionic and Zwitterionic/Nonionic Mixtures, J. Phys. Chem. B. 101 (1997) 9215-9223. DOI:10.1021/jp972099a

29. Aveyard, R., Binks, B. P., Chen, J., Esquena, J. and Fletcher, P. D. I.: Surface and Colloid Chemistry of Systems Containing Pure Sugar Surfactant, Langmuir. 14 (1998) 4699-4709. DOI:10.1021/la980519x

Received: 18. 06. 2019

Revised: 08. 10. 2019

\section{Bibliography}

DOI 10.3139/113.110660

Tenside Surf. Det.

57 (2020) 1; page 6- 12

(c) Carl Hanser Verlag $\mathrm{GmbH} \&$ Co. KG

ISSN 0932-3414

\section{Correspondence address}

\author{
Dr. John P. Hagen \\ 1 Grand Avenue \\ California Polytechnic State University \\ San Luis Obispo \\ CA 93407 \\ USA \\ Tel.: 1-805-756-165 \\ Fax: 1-8 05-756-5500 \\ E-Mail: jhagen@calpoly.edu
}

\section{The authors of this paper}

Rebecca Rowe received her BS degree in Chemistry from California Polytechnic State University in 2014. She is currently a scientist with Product Development Consulting (South San Francisco, CA)

Katherine Matasci received her BS degree in Chemistry from California Polytechnic State University in 2013. She worked at Novi LLC as a formulation chemist for two years. She is currently a research associate with Genentech (South San Francisco, CA)

Abbey Rickelmann received her BS degree in Chemistry from California Polytechnic State University in 2013. Since then, she has taught high school science. Currently she is teaching for the Los Angeles Unified School District (Los Angeles, CA)

Christine Muli received her BS degree in Biochemistry from California Polytechnic State University in 2014. After working at Genentech (San Francisco, CA) as a scientist for three years, she started her PhD studies in Medicinal Chemistry and Molecular Pharmacology at Purdue University in 2017.

Erin Doherty received her BS degree in Biochemistry from California Polytechnic State University in 2016. She is currently a National Institutes of Health (NIH) T32 Chemical Biology Predoctoral Fellow pursuing a PhD in Bioorganic Chemistry at University of California, Davis.

Travis Smith received his BS degree in Chemistry and MS degree in Polymers and Coatings from California Polytechnic State University in 2016. After working at California Polytechnic State University as a research associate for two years, he started his PhD studies in Polymers at The University of Akron in 2018

William L. Pistel, I/ received his BS degree in Chemistry from California Polytechnic State University in 2015 and MS degree in Organic Chemistry from University of California, San Diego in 2017. He is currently pursuing a MS in Nanoengineering at University of California, San Diego.

Sean Mclntyre received his BS degree in Chemistry from California Polytechnic State University in 2016. He worked as a chemist at CS Bio (Menlo Park, CA) for two years. He is currently an assistant QC chemist at Starwest Botanicals (Sacramento, CA).

Hasan Palandoken received his BS degree in Chemistry from California State University, Chico in 1993, his MS in chemistry from the University of California, Davis in 1997, and his PhD in Chemistry from University of California, Davis in 1997. He worked at Aerojet Fine Chemicals for six years and Western Kentucky University for three years. He is currently an associate professor of chemistry at California Polytechnic State University and his research interests include organic synthesis.

John Hagen received his BS degree in Chemistry from the University of Nevada, Las Vegas in 1992 and his PhD in Chemistry from Stanford University in 1996. He worked at Chatham College for five years. He is currently a professor of chemistry at California Polytechnic State University and his research interests include phase diagrams of Langmuir monolayers and the adsorption of soluble surfactants at airwater interfaces. 